\title{
Multispectral Vision for Monitoring Peach Ripeness
}

\author{
Ana Herrero-Langreo, Loredana Lunadei, Lourdes Lleó, Belén Diezma, and Margarita Ruiz-Altisent
}

\begin{abstract}
The main objective of this research was to develop an automatic procedure able to classify Rich Lady commercial peaches according to their ripeness stage through multispectral imaging techniques. A classification procedure was applied to the ratio images calculated as red $(\mathrm{R}, 680 \mathrm{~nm}$ ) divided by infrared ( $\mathrm{IR}, 800 \mathrm{~nm}$ ), that is, $\mathrm{R} / \mathrm{IR}$ images. Four imagebased ripeness reference classes (A: unripe to $\mathrm{D}$ : overripe) were generated from 380 fruit images (season 1: 2006) by a nonsupervised classification method and evaluated according to reference measurements of the ripeness of the same samples: Magness-Taylor penetrometry firmness, low-mass impact firmness, reflectance at $680 \mathrm{~nm}$ ( $\mathrm{R} 680$, and soluble solids content. The assignment of unknown sample images from those season 1 images (internal validation, $n=380$ ) and of 240 images from the 2 nd season (season 2: 2007) to the ripeness reference classes (external validation) was carried out by computing the minimum Euclidean distance (classification distance, $C_{d}$ ) between each unknown image histogram and the average histogram of each ripeness reference class. For both validation phases, firmness values decreased and $\mathrm{R} 680$ increased for increasing alphabetical order of image-based class letter, reflecting the ripening process. Moreover, $70 \%$ (season 1) and $80 \%$ (season 2) of the samples below bruise susceptibility firmness were classified into class D.
\end{abstract}

Keywords: computer vision, firmness, fruit, postharvest, ripeness

Practical Application: This work proposes and validates a procedure for assessing peach ripeness through spectral imaging. The control of ripeness in this fruit is crucial for ensuring its quality and the measurement of optimum peach ripeness at harvest and postharvest is a controversial issue, which needs to be balanced between a minimum ripeness, acceptable for the consumer, and a maximum ripeness, to minimize fruit losses during the postharvest process. The proposed method is nondestructive and quick, showing thus, a good perspective for its application in fresh fruit packing lines, either for peach ripeness assessment or for other fruits (providing adequate calibration).

\section{Introduction}

Spain is one of the most important producers of peaches and nectarines in Europe (2nd producer after Italy, with $30 \%$ of the EU production in 2007$)$ and in the world $(6.7 \%$ of world production in 2007) (Ministerio de Medio Rural y Marino de España: MMARM 2007; Macchi and others 2008; Mercasa 2008). However, for a number of years, consumption and acceptance of stone fituit is decreasing (Crisosto 2002), making the improvement of peach quality a crucial issue.

The decrease of firmness and chlorophyll content and ethylene production are the most consistent and significant changes characterizing peach ripeness (Salunkhe and others 1968; Ryall and Pentzer 1982; Couvillon and Krewer 1991; Cascales and others 2005).

Crisosto (1994) published a review on physical and chemical properties used as ripeness indexes for stone fruits. Opti- mum ripeness degree for harvest and handling is best indicated by fruit firmness, because it decreases rapidly during maturation and postharvest, determining the short period in which peaches can be stored and handled without butising (Crisosto and others 2001; Hetreto and others 2007; Valero and others 2007). MagnessTaylor firmness (MTF) thresholds telated to optimum harvest date or handling management have been established (Cemagref 1982; Crisosto 1996; Valero and others 20(07).

Quality attributes of the fruit can be estimated through a range of nondestructive (ND) techniques, involving local atea or overall measurements. Taking local atea information, low-mass impact (LI) response has been extensively used for the assessment of peach firmness (Chen and Ruiz-Altisent 1996; Gutierrez and others 2007; Valero and others 2007), while Ziosi and others (2008) defined a local optical index (Index of Absorbance Difference, $I_{A D}$ ) based on the visible spectrum allowing to differentiate 2 maturity classes of "Fayette" (yellow skin) harvest peaches, which would evolve differently during postharvest tipening. Nevertheless, it has been observed that peach fruit presents a variability in firmness and bruise susceptibility on different areas of the fruit during ripening (Crisosto and others 2001). Thus, the study of fruit properties using a technique, which allows the analysis of the whole fituit instead of local area measurements, provides relevant information, which might improve the estimation and prediction of peach ripeness. 
The study of image properties by computer vision meets the advantages of being ND, quick, accurate with spatially detailed information, and with a great potential for the automation of processes (Brosnan and Sun 2004). Most recent developments concerning image analysis in the food industry have been shown by Du and Sun (2006) and Zheng and others (2006).

Camera machine vision systems can be classified according to the electromagnetic range of the captured spectra, such as ultra violet (UV: 200 to $400 \mathrm{~nm}$ ), visible (VIS: 400 to 700 $\mathrm{nm}$ ), near infrared (NIR: 700 to $1300 \mathrm{~nm}$ ), short infrared (1300 to $2500 \mathrm{~nm}$ ), or thetmal (700 to $1000000 \mathrm{~nm}$ ); these devices acquire reflectance, transmittance, or fluorescence image from the agricultural materials. Chen and others $(2002)$ reviewing vision technology for agricultural applications describes the basis of monochrome, color, multispectral, and hyperspectral techniques.

Ground color, which can be acquired by a color vision system and specially the $a^{*}$ CIELAB cootdinate, has been traditionally used as a tipening index in peach (Fetter and others 2005). However, the use of ground color as maturity index in red skin cultitar as Rich Lady has reported to be problematic by several authors (Crisosto 1994; Tijskens and others 2007; Ziosi and others 2008), due to red blush coloration masking the ground color. The $a^{*}$ value, which relates to green-red distinction of human vision, has the disadvantage of being affected by both chlorophyll degtadation and increase in anthocyanin content during maturation and ripening (Delwiche and Baumgardner 1983; Byrne and others 1991) and thus, by any nonlinear and seasonal variations in fruit pigment contents, which can lead to inadequate interptetations (Zude-Sasse and others 2002).

In contrast to color coordinates, which combine different regions of the visible spectra, multispectral images consist of a set of several images, each one acquired at a narrow band of wavelengths (Chen and others 2002). Multispectral information allows a more direct observation of the processes or compounds, such as chlotophyll, anthocyanins, and carotenoids, associated with certain wavelengths (Merzlyak and others 20033 ).

Regarding fruit ripeness, a major issue in designing a multispectral vision system is the identification of the most relevant wavelengths. It was suggested that the most relevant spectral bands related to peach correspond to 2 areas in the visible tange: $680 \mathrm{~nm}$, the chlorophyll absotption peak, and $450 \mathrm{~nm}$, related to carotenoids content (Ruiz-Altisent and others 2006). In this work, reflectance around $680 \mathrm{~mm}$ presented the highest correlation with peach firmness, reflecting the dhlorophyll degradation during ripening.

Other authors, studying peach tipeness based on image propetries, used reflectance ratios, that is, reflectance at $680 \mathrm{~nm}$ (R) divided by that at $800 \mathrm{~nm}$ (R/IR), in order to compensate for lighting changes and shape effects (Lleó and others 2009). They used multispectral imaging for the unsupervised aggregation of $\mathrm{R} / \mathrm{IR}$ peach images into 4 classes related with peach ripeness (4 redskin early melting varieties were metged), obtaining good correspondence with reference values (MTF, impact acceletation and equatorial reflectance at $680 \mathrm{~mm}$ ), for which significant differences were found between all groups for MTF and equatorial reflectance at $680 \mathrm{~nm}$.

Reflectance ratios have been widely used as optical indexes for other applications, as in the Normalized Difference Vegetationt Index, and in the Red Ratio Vegetation Index, (Scotford and Millet 2005). Those indexes have been shown to compensate even very large lighting variations, such as those registered under remote sensing
(Basso and others 2001; Scotford and Miller 2005; Xue and Yang 2009).

The main objectives of this work are

(1) To test and validate the procedure proposed by Lleó and others $(2009)$ for peach ripeness classification using multispectral images in 2 channels (centered at $680 \mathrm{~nm}$ and 800 nm). This at ticle aims to validate this procedure for a single variety, "Richlady," along several seasons, proving its capacity to classify unknown samples into previously generated ripeness classes.

(2) To evaluate this procedure for monitoring peach ripeness, in ordet to analyze the potential of the developed method to supervise and predict peach ripening along the postharvest process.

(3) To evaluate and overcome some of the first limiting factors for its potential applicability for online postharvest peach ripeness assessment: robustness and automation of the procedure.

Two of the main difficulties for assessing peach tipeness ate its quick development both in the tree and during postharvest and the high susceptibility to be affected by seasonal or handling effects. The generation a priori of reference classes gathering the whole vatiability to be found along a campaign is thus difficult to achieve. Therefore, any procedure proposed to classify peach ripeness needs to be able to handle and identify samples not represented in the original reference model. The robustness of the proposed imagebased ripeness classification was tested using data from 2 seasons, and a limitation critetion was proposed to avoid misclassification of samples out of the range of the reference model.

Automated routines were developed with MatLab (version 7.0, Math Works, Inc., USA) in order to minimize human intervention in the classification procedure.

In the previous work by Lleó and others $(2009)$, an additional limitation was observed regarding the segmentation approach. In this previous work, a fixed intensity level was used to threshold the peach image from the background. This method has the inconvenient of requiring constant ranges of intensity correspondent to the objects of interest and to the background. Furthermore, the validity of the chosen threshold has to be manually checked for new datasets. In order to automate the image segmentation, 2 threshold techniques are considered for the analysis and compared: Otsu method (Otsu 1979) and Triangle Algorithm (Zack 1977).

\section{Materials and Methods}

\section{Fruit samples}

The experiment was carried out during 2 seasons (2006 and 2007) on red soft-flesh peaches (cultivar Rich Lady). In 2006 (season 1), peaches were hand harvested from an orchard in Murcia (Spain) on 3 dates: commetcial harvest date $\left(\mathrm{H}_{2}\right), 1 \mathrm{wk}$ in advance $\left(\mathrm{H}_{1}\right)$, and $1 \mathrm{wk}$ after $\left(\mathrm{H}_{3}\right)$. As fruit quality properties can vary significantly depending on the fruit area or fruit side, 2 areas, considered to be divided by the suture of the fruit, were differentiated when taking the measurements: the most colored side, or Blush (B), and the least colored side, or Grontd (G). Single fruit sides wete considered as sample units in this work. For each harvest date, peaches were divided into 3 groups: (1) Commercial: 160 fruits (320 fruit sides) measured $1 \mathrm{~d}$ after harvest; (2) Ripened: A randomized subgroup of 60 fruit sides was measured after being cooled $4 \mathrm{~d}$ at $2{ }^{\circ} \mathrm{C}$ and $2 \mathrm{~d}$ at $7{ }^{\circ} \mathrm{C}$, and further on, ripened $3 \mathrm{~d}$ at $20^{\circ} \mathrm{C}$. This population was considered on the classification procedure in order to include overripe samples; 
(3) Montitored: an additional batch of 60 fruits (20 from each hatvest date), monitored along the cooling and ripening process (120) fruit sides). The applied treatments emulate the postharvest chain from harvest to selling point in the United States (Crisosto 2006). In 2007 (season 2), in otder to obtain a wider tipeness tange, 5 harvest dates wete considered: commercial harvest date $\left(\mathrm{H}_{4}\right)$; 1 wk later $\left(\mathrm{H}_{5}\right)$; and 1,2 , and $3 \mathrm{wk}$ in advance $\left(\mathrm{H}_{3}, \mathrm{H}_{2}\right.$, and $\mathrm{H}_{1}$ ). Similar treatments as in season 1 were applied for each harvest, considering 100 fruits for Conmercial treatment and 20 fruits for Ripened treatment. Thirty fruits were monitored along the process.

A total of 500 samples (fituit sides) were considered for the analysis in 2006 (380 for image-based classes generation +120 for ripeness monitoring purposes) and 300 in 2007 (240 for image-based classes evaluation +60 for ripeness monitoring purposes).

\section{Methods}

ND reference tests (LI firmness, visible relative reflectance spectra), image acquisition, and destructive (D) reference tests (MTF and soluble solids content [SSC]) were carried out on Commerial and Ripened samples. The postharvest evolution of the Monitored samples was individually assessed through ND techniques along the emulated postharvest process (that is, LI firmmess, visible reflectance spectra, and image), being destroyed and tested destructively at the end of the ripening process.

Reference measurements. The following measurements were considered:

LI firmmess. Measured by averages of 3 impact responses, the maximum impact acceleration $\left(\mathrm{m} / \mathrm{s}^{2}\right)$ was measured using the "LPF-Latetal Impact Sensor 2.0" (Diezma-Iglesias and others 2006 ).

$M T$ pettetrometry firmess. Maximum penetration force, MTF, in $\mathrm{N}$, was measured with a Texture Analyzer TA-XT2 (Stable Micro Systems Ltd., Godalming, U.K.) using an 8-mm dia rod, at a deformation rate of $20 \mathrm{~mm} / \mathrm{min}$. Averages of 3 measurements were computed.

Solitble solids contint. Soluble solids were determinate on some drops of squeezed juice by a digital reftactometer ATAGO PR-101 (ATAGO Co., Ltd., Bellevue, U.S.A.) and values were expressed in ${ }^{\circ}$ Brix. Soluble solids are correlated with the sweetness of peaches, consisting mainly of sucrose, glucose, and fructose (Wu and others 2005).

Optical reflectance. Visible relative reflectance spectra 400 to 700 nm, at 20-nm intervals, was obtained with a portable spectrophotometer Minolta CM-508I (Konica Minolta Sensing, Inc., Japan). Average reflectance at $680 \mathrm{~nm}(\mathrm{R} 680)$ was used in this work as ripening reference data for multispectral analysis.

Image acquisition. Images were acquired through a multispectral image system consisting of a frame-grabber (Natl. Instruments ${ }^{6}$, Austin, Tex., U.S.A.) and a 3 CCD camera (Duncan Tedh/Redlake MS-310 $0^{(B)}$, Redlake Inc., U.S.A.) with digital output. Cameta resolution was $1392 \times 1039$ pixels, endowed with 3 band-pass filters (band-width: $20 \mathrm{~nm}$ ), centered at $800 \mathrm{~nm}, 680 \mathrm{~nm}$, and $450 \mathrm{~nm}$. The light source was provided by 6 $100 \mathrm{~W} / 220 \mathrm{~V}$ halogen lamps and the object distance between the lens system and the sample was $60 \mathrm{~cm}$. The images were acquired using a black background. A black canvas was put around the vision test station, in order to create a uniform light field around the object and to eliminate any effect of envitonmental light.
Preprocessing: image segmentation and calculation of ratio images.

Inage segmentation. Peaches were distinguished from the background through the Triangle Algorithm thresholding segmentation (Zack 1977). This technique computes the threshold level based on the image histogram distribution. It was petformed on the IR images, since they presented the greatest difference between the gray levels corresponding to fruit (the region of interest [ROI]) and to background. This segmentation method was useful in this work because in the histograms of the IR images the ROI produced a low peak, due to a wide range of intensities comprising the object image, while backgtound pixels wete distributed on a natrow range of gray levels, producing a dominant peak in the histogram (Rekik and others 2007). The explained variance $\left(R^{2}\right)$ between the size measured on the fruit and the estimated size of the ROI in the segmented images was calculated in order to compare the Triandele Alootithm segmentation with the Otsu metitod (Otsu 1979), a segmentation technique very commonly used in the bibliogtaphy. Otsu (1979) algorithm for atomatic threshold is based on discriminant analysis and maximizes the between-class variance of the histogram to give the best separation. This method is based on the assumption of Gaussian (Normal) distribution of both, the sample and the background histogram. Thus, as observed by HuiFuang (2006), it requires the image histogram to be bimodal. In turn, triangle algotithm was first described by Zack (1977). The method is based in finding the threshold intensity assuming it is located on the first valley of the histogram aside of the background peak. This technique is particularly effective when the ROI (the fruit image in this case) produces a weak peak in the histogram, while background pixels present similar intensity levels, producing a dominant peak (Rekik and others 2007). The application of this principle is not affected by the kind of statistical distribution of the histogram and tolerates irregularities on the sample. Otsu method is a very common technique used in image thresholding, because it requires a very small rumning time and it is readily available in most image processing software. Nevertheless, the fituit images used presented some irregularities, such as high colored blotches on the fruit and irregularities on the background like holding platforms for the fruit (darker than the general black background), affecting to $O$ tsu segmentation method. Thus, both methods were compared in ordet to optimize the frtit image segmentation.

As fruit size was measured perpendicularly to the tip axis line, it was estimated as the minor axis from the segmented images of the fruit.

Ratio inages alalation. The ratio images red $(\mathrm{R})$ divide by infrated (IR), R/IR, were computed for each sample and futthet analysis was based on the histograms of those tatio images. The histogtams of the ratio images, computed as pixels distribution over the range of $\mathrm{R} / \mathrm{IR}$ values of the images, were used for all further analysis and classifications.

\section{Image classification.}

Nonstipervised inate classification. A nonsupervised classification according to Ward's method (Ward 1963) was performed in order to define ripeness reference cliss based on the histograms of the ratio images of a learning dataset. A multidimensional space was considered, where each dimension corresponded to an intensity level of the R/IR histograms. Each histogram was thus represented as a single point on the multidimensional space. Ward's classification method was applied by computing the matrix of Euclidean distances (EDs) between each pair of individuals (histograms), grouping the closest individuals, and hietarchically merging groups 
(or individuals) whose combination gave the least Ward Linkage distance, that is, the minimum increase within sum of squares of the new-formed group. As an advantage to other classification methods, Ward's method takes into account all histograms of the learning dataset at every level of the grouping, producing very well structured and homogeneous groups (Otto 2007). A routine was developed in MatLab 7.0 in order to generate the groups according to Ward's Method. In this routine, the maximum value of Ward Linkage distance allowed between groups is entered as an input for computing the nonsupervised classification. The average histogram was computed for each generated group and defined as ripeness reference class.

Calibration: Generation of ripeness reference classes. In order to generate image-based ripeness reference classes, including commercial and overripe fruits from season 1, a nonsupervised classification according to Ward's method was performed on 380 images: 320 images from Commerial fruits and a randomized selection of 60 images from Ripened ones. Those images were included in order to consider unmarketable overripe peaches, which should be rejected at the packing line.

Validation: Classification of unknown samples into ripeness reference classes. A validation procedure was developed to assess the errors in real-time classification of unknown images. Internal, external, and crossed validations were successively carried out always assigning unknown individuals into the previously generated ripeness reference classes. Each unknown histogram was classified into the reference class (each one defined by the average histogram of the class) to which it computed the minimum Euclidean classification distance $\left(\mathrm{C}_{\mathrm{d}}\right)$.

For internal validation, the same population generating the model was classified again into the ripeness reference classes: the observed classification of the samples was compared with the predicted classification of the same sample, obtained by computing the EDs between the histogram of the samples image and the average histograms of the generated ripeness reference classes.

On cross-validation (leave-one-out), the observed (calibration) classification was generated by 379 histograms (Commercial and Ripened) through nonsupervised Ward's method. The predicted classification of each unknown histogram was obtained through the minimum ED to the ripeness reference classes generated with the remaining population $(n=379)$.

Finally, in order to test the robustness of model based on season 1 data, it was validated with season 2 samples. Season 2 population included a wider range of ripeness stages than season 1 , considering fruits from up to $3 \mathrm{wk}$ prior to commercial harvest date. Therefore, a limitation criterion was needed to exclude from the validation classification those samples that were not represented in the model generated from season 1 data. Otherwise, samples that cannot be considered as similar to any of the reference classes would be assigned to the closest of them and consequently misclassified. The maximum classification distance obtained in the internal validation for the observations, which generated each reference class, was considered as the maximum classification distance allowed for unknown observations.

A total of 200 samples from fruits measured $1 \mathrm{~d}$ after harvests on season 2, plus 40 samples randomly selected from Ripened samples from commercial and postcommercial harvest, were considered: their corresponding histograms $(n=240)$ were classified into the ripeness reference classes generated from season 1 data $(n=380)$.

Evolution. The postharvest ripeness evolution was monitored using the calculated image-based classification system on 60 sam- ples from season 1 and also with 40 samples from season 2 . The image-based classification of fruit samples calculated $1 \mathrm{~d}$ after harvest was compared with the image-based classification and the reference measurements of the same fruits after the ripening process.

Statistical analysis. The reference parameters (LI firmness, MTF, SSC, and R680) were compared to the classification based on the histograms of the images. Analysis of variance analysis was applied to the reference parameters and to the classes extracted from the image analysis. The analysis of the images was carried out using Matlab ${ }^{(B)}$ and Statistica ${ }^{(v)}$ (version 6.0, StatSoft, Inc., Tulsa, Okla., U.S.A.).

\section{Results}

\section{Segmentation and calculation of ratio images}

Figure 1 shows an example of a fruit image and its histogram segmented by the Triangle (a) and Otsu (b) procedures. When compared to the Otsu method, the explained variance between the measured size of fruits and the image estimated size improved from $90 \%$ (Otsu) to $96 \%$ for the Triangle Algorithm segmented images. This improvement on the segmentation can be explained because then Otsu method requires bimodal histograms to be applied. Instead, in the data obtained, the histograms of the images did not always present a bimodal distribution (that is, images produced 1,2 , or 3 peaks due to red blushed patches and to the eventual presence of the platform supporting the fruit), this affecting the segmentation performance of the Otsu method. The tips of the fruits were the areas for which the Triangle Algorithm showed better discrimination (Figure 1).
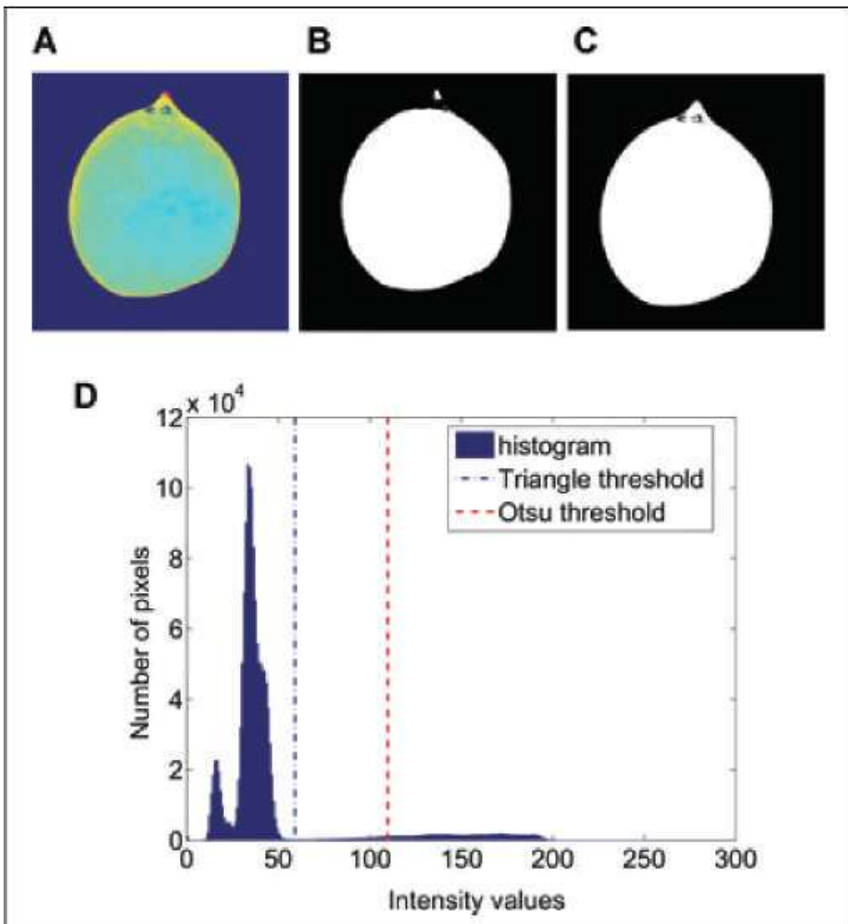

Figure 1-Image segmentation: (A) $R / I R$ image; (B) triangle segmented binary image; (C) Otsu segmented binary image; (D) IR histogram (the red and the blue lines represent the intensity values corresponding to the threshold level obtained respectively through Otsu method and Triangle Algorithm application). 


\section{Calibration: Generation of ripeness reference classes}

Figure 2A plots the dendrogram generated by Ward's nonsupervised classification. The hierarchical grouping of the population according to Ward Linkage distance was observed for 380 Commercial and Ripened images from season 1. According to this grouping, 4 ripeness reference classes (A to D) were obtained when setting the maximum Ward Linkage distance within groups at 150000 pixels. Figure $2 \mathrm{~B}$ shows the average histograms for each class.

Figure 3 plots the average values and confidence intervals (95\%) of the reference quality parameters for each image-based class. Image-based classes were ordered according to the mode of their $\mathrm{R} / \mathrm{IR}$ histograms and named from $\mathrm{A}$ to $\mathrm{D}$. Thus, the histogram mode, moved toward higher $\mathrm{R} / \mathrm{IR}$ reflecting chlorophyll degradation from A to D. Both MTF and LI firmness values were highly coincident with the nonsupervised image classification, showing a consistent decrease of firmness from classes A to D. According to MTF, classes A and B are not significantly different and could be grouped and identified as unripe, while class $\mathrm{C}$ corresponds to medium and class D to ripened fruits (Figure 3A). LI firmness was able to discriminate between all the image-based classes (Figure 3B). The best accordance between the image-based classes and their reference values was shown by R680, as expected (Figure 3C). It is thus observed that the developed procedure and the model would be able to reflect the softening and chlorophyll degradation associated with peach ripening (Cascales and others 2005). Only one class presented significant differences regarding $\mathrm{SSC}$, class D with significantly higher values than those from classes $\mathrm{A}, \mathrm{B}$, and C (Figure 3D). This fact is explained by the low range of variability of SSC within the population (10.5 to $11.8^{\circ} \mathrm{Brix}$, as usually found in commercial production). While other fruits do metabolize starch into sugars during ripening, very low quantities of starch have been found at any stage of peach development (Chalmers and Ende 1975). Accordingly, other works studying visible spectra of peach have detected no significant evolution of SSC during peach ripening (Ruiz-Altisent and others 2006; Ziosi and others 2008). Nevertheless, the use of IR spectroscopy allowed the estimation of SSC in stone fruits (Peiris and others 1998; Slaughter and others 2003; Carlomagno and others 2004; Camps and Christen 2009; Pérez-Marín and others 2009). In all those cases, it was used the NIRS spectral region (700 to 2500 $\mathrm{nm})$ instead the visible $(680 \mathrm{~nm})$ one used in the present paper. Furthermore, samples used had a higher variability of SSC values.

Figure 4 shows one sample of an $\mathrm{R} / \mathrm{IR}$ image of each nonsupervised class (A, B, C, and D): increasing $R / I R$ values are observed for higher ripeness image classes. This effect was observed by other authors in local spectral measurements; Delwiche and others (1987) investigated color and spectral variations in peaches at various maturity stages. They tested several indexes and proposed spectral index R670/R 800 for maturity sorting (reflectance at 670 $\mathrm{nm}$ normalized by that at $800 \mathrm{~nm}$ ) finding a correlation with firmness of $r^{2}=0.6$, pooling 9 peach varieties. Significant differences in R670/R800 measurements among varieties indicated that sorting equipment would need to be adjusted according to cultivar. Merzlyak and others (2003) tested the index R800/R678 in apples, finding it linearly related to chlorophyll content in the range 0.4 to $5 \mathrm{nmol} / \mathrm{cm}^{2}$, and saturated when chlorophyll exceeded 6 $\mathrm{nmol} / \mathrm{cm}^{2}$. No saturation of the R/IR index used for image classification is suggested by the observed histograms (Figure 2B) and fruit images (Figure 4).

As shown in Figure 4, through using spatially detailed measurements (imaging), at the same time, areas with different ripeness can be distinguished within each fruit.

MTF thresholds were considered according to the bibliography: Crisosto (1996) recommended special controlled ripening treatment for peaches above $53 \mathrm{~N}$ MTF, while the maximum MTF values for harvesting peach were established at $45 \mathrm{~N}$ by Cemagref (1982). The usual MTF range used in packing and processing lines in California was set between $35 \mathrm{~N}$ and $45 \mathrm{~N}$ (Crisosto 1996), finding that fruit below $35 \mathrm{~N}$ was significantly more susceptible to be bruised (Crisosto and others 2001). Peaches between $18 \mathrm{~N}$ and $35 \mathrm{~N}$ were described by (Valero and others 2007) as ready to buy and peaches below $18 \mathrm{~N}$ as ready to eat and no longer commercial.

Table 1 displays the number of season 1 samples assigned to each image-based class, according to Ward's nonsupervised classification, categorized in their corresponding one by one MT ranges. Considering the mentioned firmness thresholds, $82 \%$ of the samples assigned to classes A or B would be above the recommended firmness for harvest (MTF $>53 \mathrm{~N}$ ), while $80 \%$ of
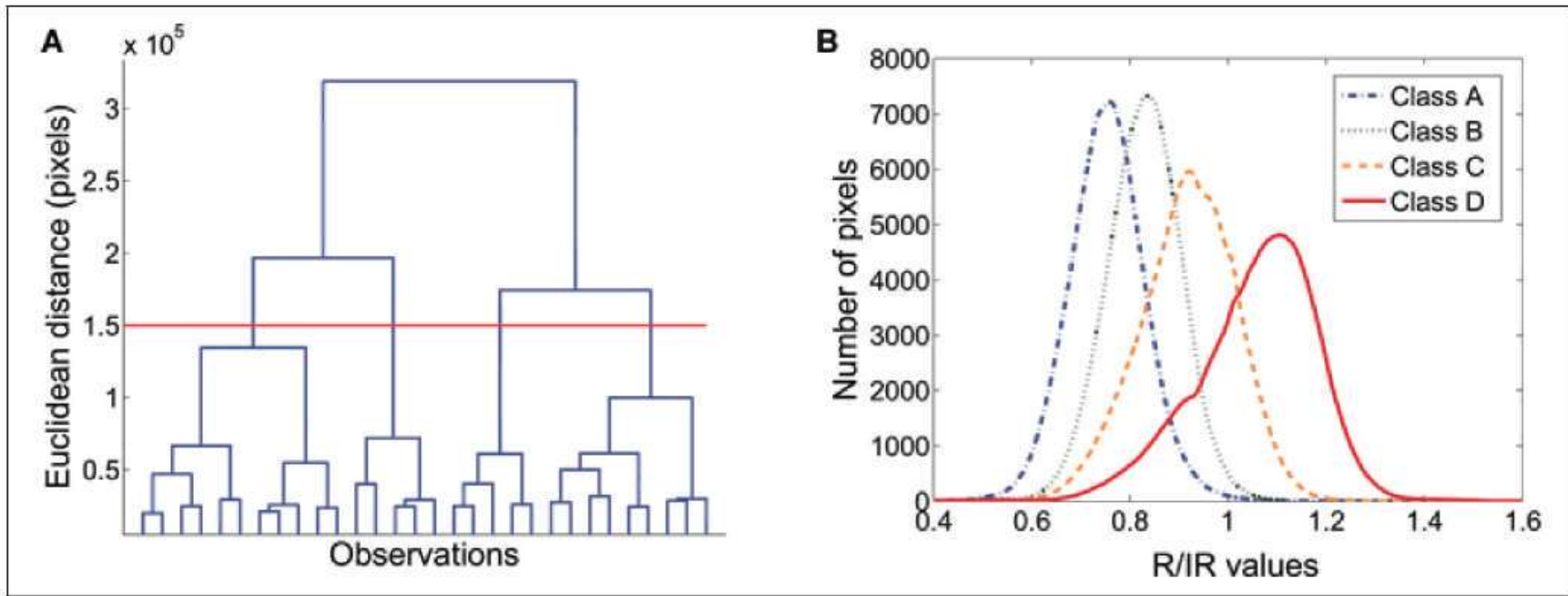

Figure 2-Ripeness reference classes generation for $n=380$ ( $n=320$ at harvest, $n=60$ overripe) according to Ward's method: (A) dendrogram with 4 classes that show linkage Euclidean distances $<1.5 \times 105$ pixels; $(B)$ average histograms of the generated ripeness reference classes. The hist ograms represent the distribution of pixels ( $y$-axis), over $R / I R$ values of the images ( $x$-axis). 
those assigned to class $\mathrm{D}$ would be unmarketable for processing, distribution, and retailing (MTF $<18 \mathrm{~N})$. Class $\mathrm{C}$ contained $72 \%$ of the samples within the usual firmness range at packing lines ( 35 to $45 \mathrm{~N}$ ), and $81 \%$ of the samples assigned to this class was comprised between the thresholds of unmarketable soft fruits and fruits needing special ripening treatment $(18$ to $53 \mathrm{~N}$ ). According to these results, image-based classes may provide relevant information for the management of peach packing houses, showing good potential to select most unmarketable soft fruits and fruits needing ripeness treatment. These results confirm and improve previous work by (Lleó and others 2009), who compared R with R/IR image-based classifications, computed by Ward's nonsupervised classification and applied to 420 samples from 4 pooled redskin peach varieties. In this work, MTF was lower than $25 \mathrm{~N}$ for $82 \%$ of the fruits belonging to the ripest $\mathrm{R} / \mathrm{IR}$ class and over $25 \mathrm{~N}$ for $87 \%$ of fruits on the most unripe $\mathrm{R} / \mathrm{IR}$ class.

These improved results, centered on a single variety allowed testing the validation procedure, which would assign unknown

\section{A}

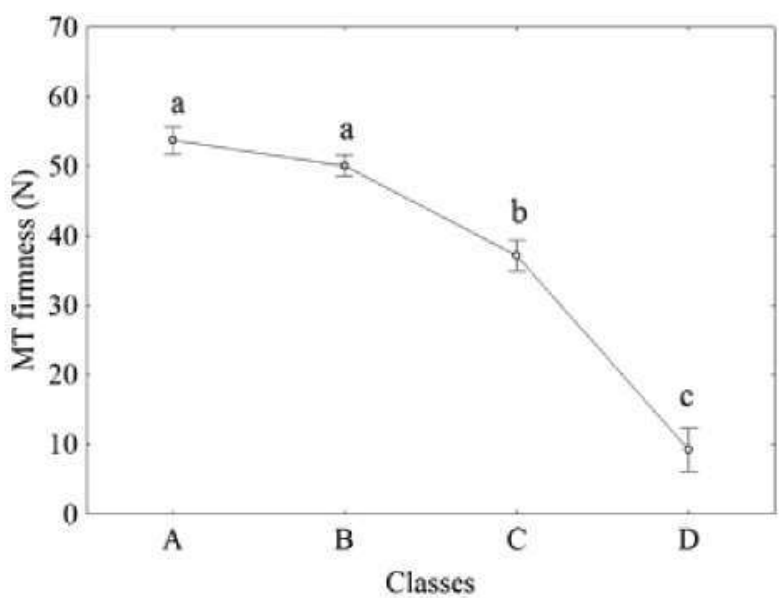

C

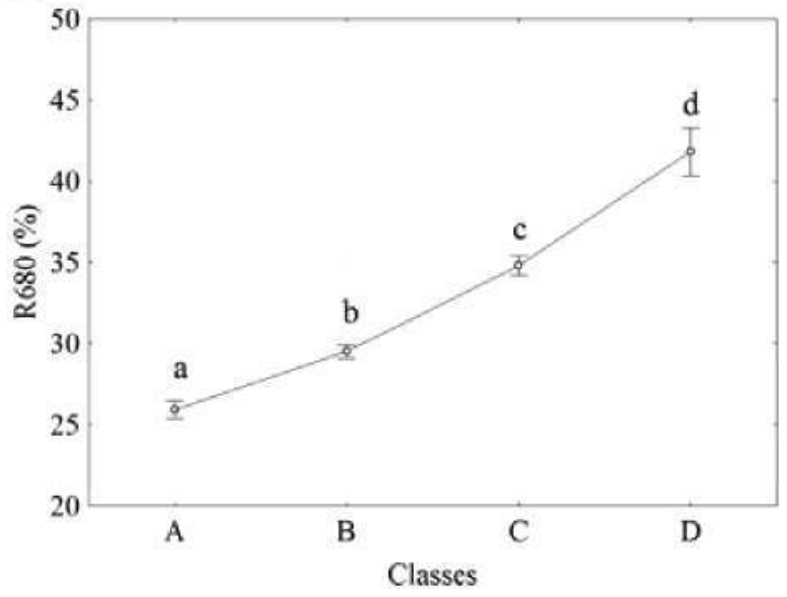

B

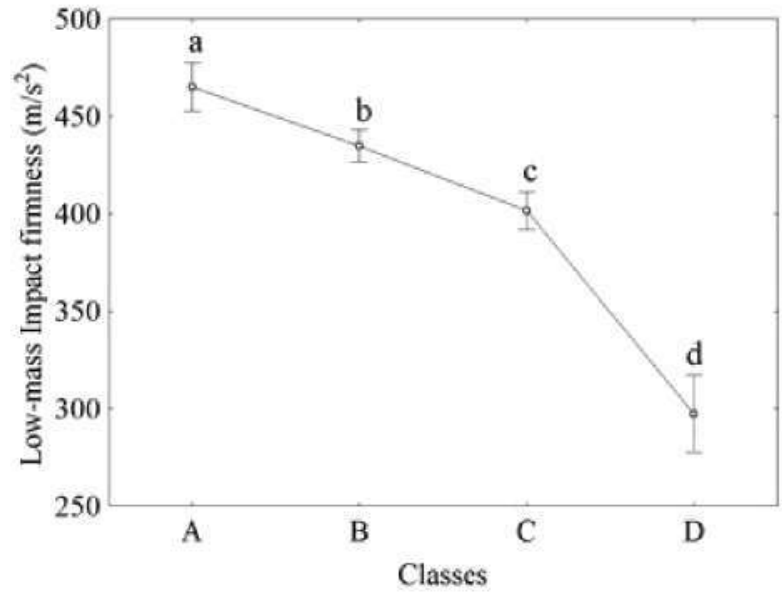

D

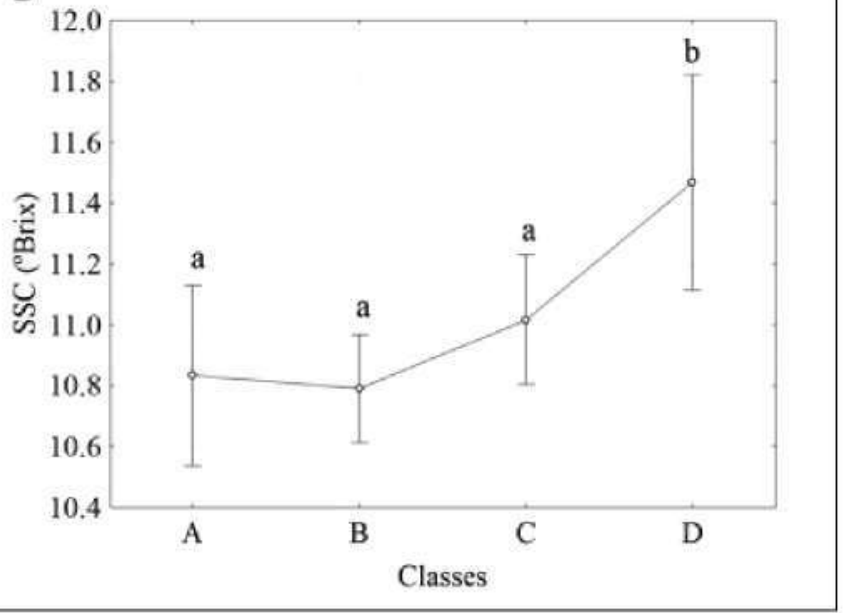

Figure 3-Plot of averages and confidence intervals (95\%) of 380 samples from season 1, classified in classes A to D according to Ward's method: (A) Magness-Taylor (MT) firmness, (N); (B) low-mass impact firmness (m/s2); (C) reflectance at $680 \mathrm{~nm}(\mathrm{R} 680$, in \%); (D) soluble solids content (SSC, in ${ }^{\circ}$ Brix). Lowercase letters represent significant differences between classes at $P<0.05$ according to LSD test.

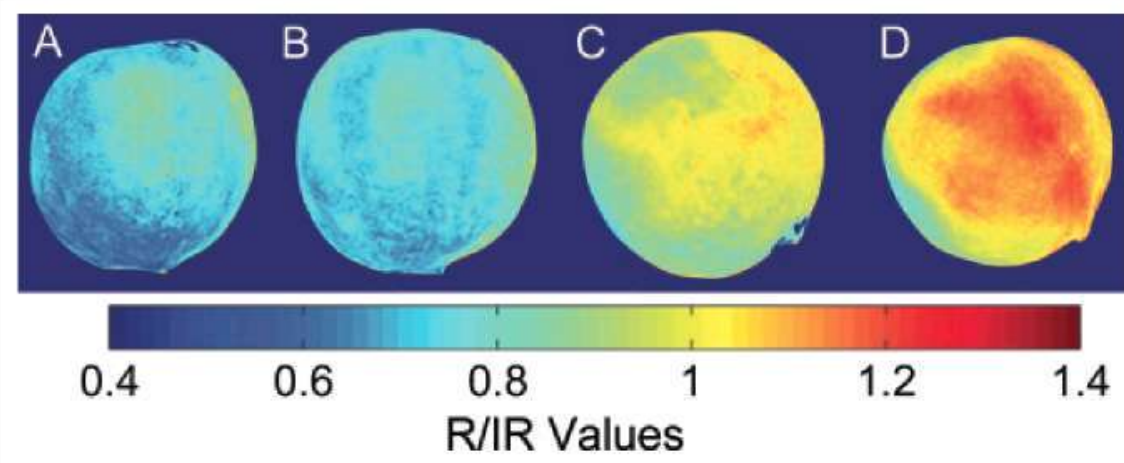

Figure 4-R/IR example images from image-based classes $A, B, C$, and D (color scale represents $R / I R$ intensity values of the images). 
samples from 1st and 2 nd season, to these nonsupervised imagebased classes.

\section{Internal and cross-validation}

Regarding the internal validation of the model ( $n=380), 92 \%$ of the samples were classified into the same group by both methods: the Ward's nonsupervised classification (ripeness reference classes A to D) and the classification according to the minimum EDs to Ward generated reference classes (Table not shown). The maximum $\mathrm{C}_{\mathrm{d}}$, used as limitation criteria for external validation, was 36.587 pixels.

Regarding the cross-validation, $88 \%$ of the images were classified on the same group by both methods (Table 2).

\section{External validation}

The proposed classification procedure, obtained through the minimum ED to the reference classes and generated in season 1 , was able to classify correctly 147 from the 240 samples considered from season 2 . The procedure automatically excluded 93 histograms, which were named as class 0 (see 3.3).

As observed in the Figure 5, unknown samples assigned to class D by classification distances higher than the maximum classification distance obtained for class $\mathrm{D}$ in the internal validation (Max-Cd. class D) presented very low $\mathrm{R} / \mathrm{IR}$ mode values. In addition, these histograms corresponded to very immature peaches harvested 3 wk prior to commercial harvest and could be thus considered as misclassified. This result could be explained because no such unripe fruit was included in the dataset generating the model in season 1 , so that no similar samples were represented in the model.

In order to avoid this misclassification, samples with a classification distance greater than the maximum classification distance obtained for each class in the internal validation were excluded as "unclassified" and assigned to class 0 . As an alternative, in order to simplify the classification procedure, an equivalent single maximum classification distance could be considered. As observed in Figure 5 , the same result is obtained by excluding observations with a classification distance higher than the maximum classifi-

Table 1-Categorized assignment of season 1 images $(n=380)$, according to image-based classes (Ward's classification), related to Magness-Taylor (MT) firmness ranges.

\begin{tabular}{|c|c|c|c|c|c|}
\hline \multirow{2}{*}{$\begin{array}{l}\text { Ripeness reference } \\
\text { classes. Season } 1\end{array}$} & \multicolumn{5}{|c|}{ MT firmness ranges $(\mathrm{N})$} \\
\hline & $>53$ & 45 to -53 & 35 to -45 & 18 to 35 & $<18$ \\
\hline Class A & 26 & 22 & 3 & 0 & 0 \\
\hline Class B & 55 & 47 & 23 & 7 & 1 \\
\hline Class C & 12 & 24 & 68 & 27 & 16 \\
\hline Class D & 0 & 1 & 0 & 9 & 39 \\
\hline
\end{tabular}

Table 2- Minimum Euclidean distance classification by crossvalidation (leaving-one-out) against reference camera classification (Ward's method, $n=380$ from season 1 ).

\begin{tabular}{|c|c|c|c|c|c|c|}
\hline \multirow{2}{*}{$\begin{array}{l}\text { Reference camera } \\
\text { classification (Ward's } \\
\text { method). OBSERVED }\end{array}$} & \multicolumn{5}{|c|}{$\begin{array}{c}\text { Minimum Euclidean } \\
\text { distance } \\
\text { classification. Cross } \\
\text {-validation. } \\
\text { PREDICTED }\end{array}$} & \multirow{2}{*}{$\begin{array}{l}\text { Percentage of } \\
\text { correctly } \\
\text { classified }(\%)\end{array}$} \\
\hline & Cluster & A & B & C & D & \\
\hline & A & 50 & 1 & 0 & 0 & 98 \\
\hline & B & 16 & 113 & 4 & 0 & 85 \\
\hline & C & 0 & 10 & 126 & 11 & 86 \\
\hline & D & 0 & 0 & 2 & 47 & 96 \\
\hline
\end{tabular}

cation distance for all classes multiplied by $0.8\left(\mathrm{C}_{\mathrm{d}}>\mathrm{C}_{\mathrm{d} \text {,max }} \times\right.$ $0.8)$.

Those histograms were considered out of the range of the model, resulting that $92 \%$ of them had MTF higher than $65 \mathrm{~N}$, well above the highest value recommended at harvested and therefore not commercial.

Figure 6 shows the scatter plot of MTF against R680 for each sample and image-based classes. A nonlinear relationship between both variables can be observed, as well as an ordered segregation of image-based classes along the model.

Table 3 displays the number of samples classified on each imagebased class (through minimum ED classification to season 1 ripeness reference classes) categorized by their corresponding MTF ranges. According to the aforementioned MTF thresholds, $85 \%$ of the samples assigned to class $\mathrm{A}$ would need special ripening treatment, while $85 \%$ of samples assigned to class A or B would be above the recommended firmness for harvest. As a potential rejection criterion for soft fruits, $73 \%$ of the population assigned to class D would be unmarketable for processing, distribution, and retailing. Class C contained $59 \%$ of the samples within the usual firmness range in packing lines, while $30 \%$ were contained in class B.

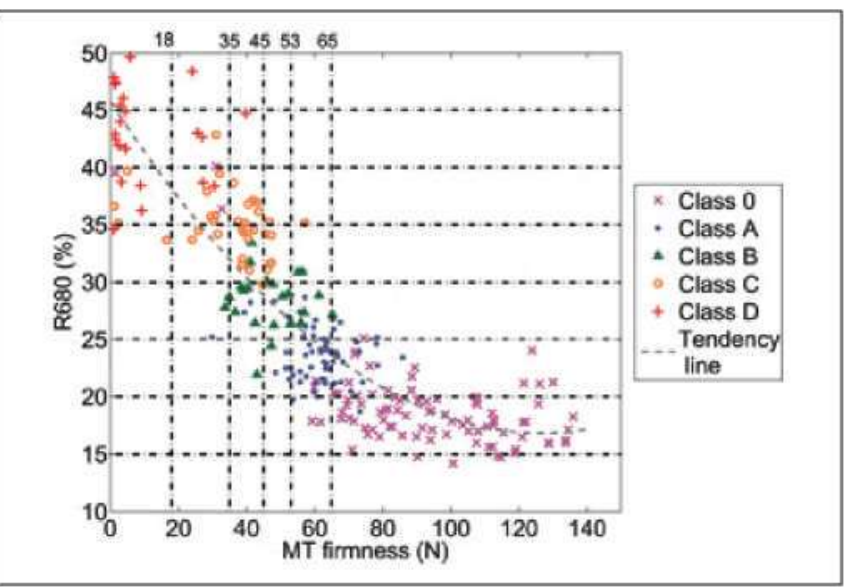

Figure $5-R / I R$ histogram mode value against the classification distance for each image ( $n=240$ from season 2). Color lines indicate maximum classification distances obtained for each class in the internal validation.

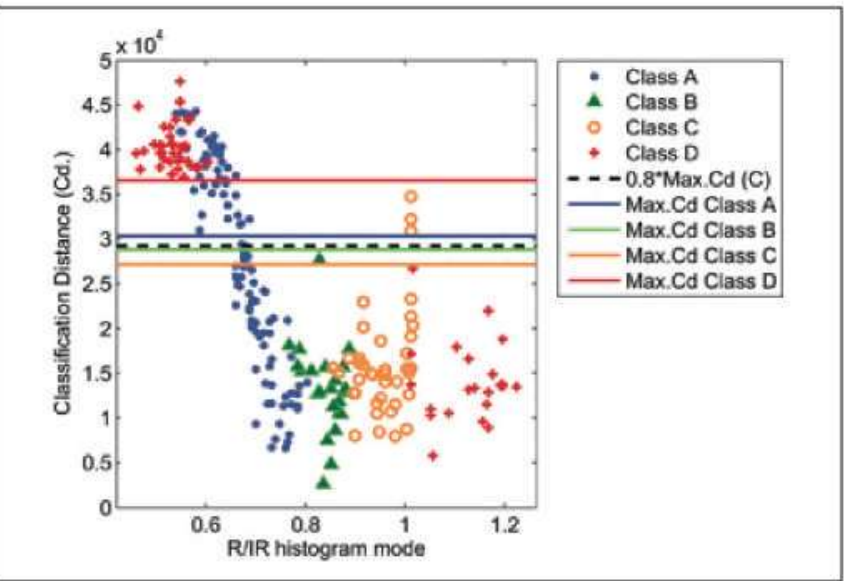

Figure 6-Scatter plot for Magness-Taylor (MT) firmness (N) against Reflectance at 680 (R680, in \%). Dot colors and shapes represent the assigned image-based class for the external validation $(n=240$ from season 2) classified with the season 1 model. 
Figute 7 plots average values of the reference quality parameters for each image-based class of the A to D classified population ( $n=147$ ). MTF, for classes $\mathrm{B}$ to $\mathrm{D}$ (Figure $7 \mathrm{~A}$ ) and $\mathrm{R} 680$ for all classes (Figure $7 \mathrm{C}$ ) showed similar average values to season 1 ripetiess reference dasies. Samples assigned to class A showed higher MTF values on season 2, resulting on significant differences between classes $\mathrm{A}$ and $\mathrm{B}$. This is due to the wider firmness range of the population of season 2. LI firmness values (Figure 7B) decreased significantly from classes $A$ to $D$, but their values were lower in season 2 as compared to season 1 . Range of vatiability in SSC was narrowet in season 2 , and the image- based classes do not show any significant differences, as in season 1 (Figure 7D).

\section{Evolution}

When comparing the image-based classification before and after the ripening process on season 1 ( $n=113$ samples, Table 4), it was observed that $22 \%$ of the images were classified in the same class ( $A$ to $D$ ) before and after the ripeness process, while $68 \%$ evolved one class and $8 \%$ evolved 2 classes. In season 2 ( $n=43$ samples, Table 5), those proportions were $19 \%, 67 \%$, and $7 \%$, highly similat. The rest of Montitored images, measured for

Table 3-Categorized assignment of season 2 images $(n=240)$, according to image classification based on minimum Euclidean distance to season 1 ripeness reference classes, related to $M T$ firmness ranges.

\begin{tabular}{lcccccc}
\hline & \multicolumn{5}{c}{ MT firmness ranges (N) } \\
\cline { 2 - 7 } Ward classes. Season $\mathbf{2}$ & $\mathbf{5 3}$ & $\mathbf{4 5}$ to $\mathbf{5 3}$ & $\mathbf{3 5}$ to $\mathbf{4 5}$ & $\mathbf{1 8}$ to $\mathbf{3 5}$ & $<18$ \\
\hline Class A & 56 & 7 & 2 & 1 & 0 \\
Class B & 6 & 7 & 8 & 2 & 0 \\
Class C & 1 & 6 & $\mathbf{1 6}$ & 9 & 4 \\
Class D & 0 & 0 & $\mathbf{1}$ & 5 & $\mathbf{1 6}$ \\
Class 0 & 90 & 0 & 0 & 2 & $\mathbf{1}$ \\
\hline
\end{tabular}

Table 4-Image-based class after ripening process fyainst class at harvest process $(n=120$ from season 1$)$.

\begin{tabular}{lccccccc}
\hline & \multicolumn{7}{c}{ At harvest. Season 1. } \\
\cline { 2 - 7 } After ripening. OBSERVED & Cluster & A & B & C & D & $\mathbf{0}$ \\
\hline & A & 2 & 1 & 0 & 0 & 0 \\
& B & 9 & 7 & 0 & 0 & 0 \\
& C & 1 & 29 & 9 & 1 & 1 \\
& D & 0 & 8 & 39 & 7 & 0 \\
& 0 & 0 & 2 & 0 & 0 & 4 \\
\hline
\end{tabular}

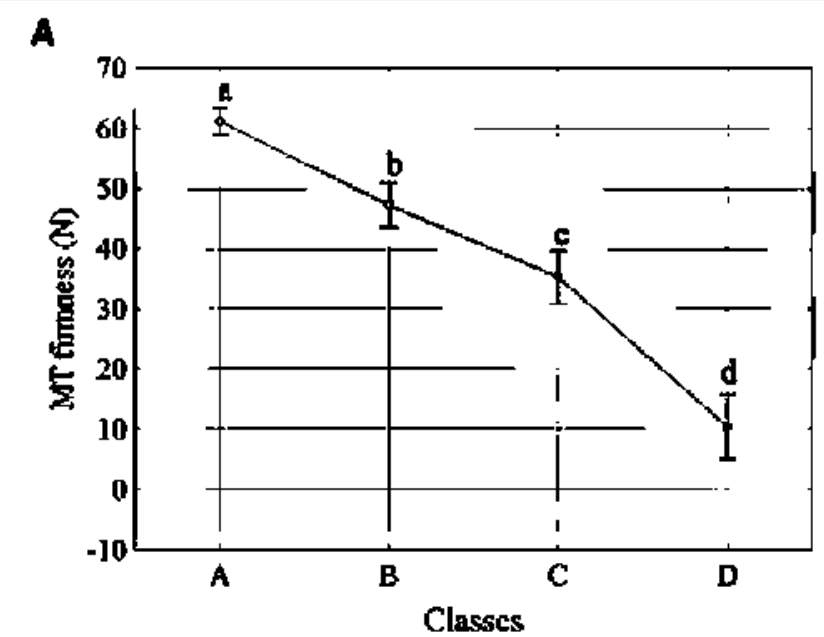

B
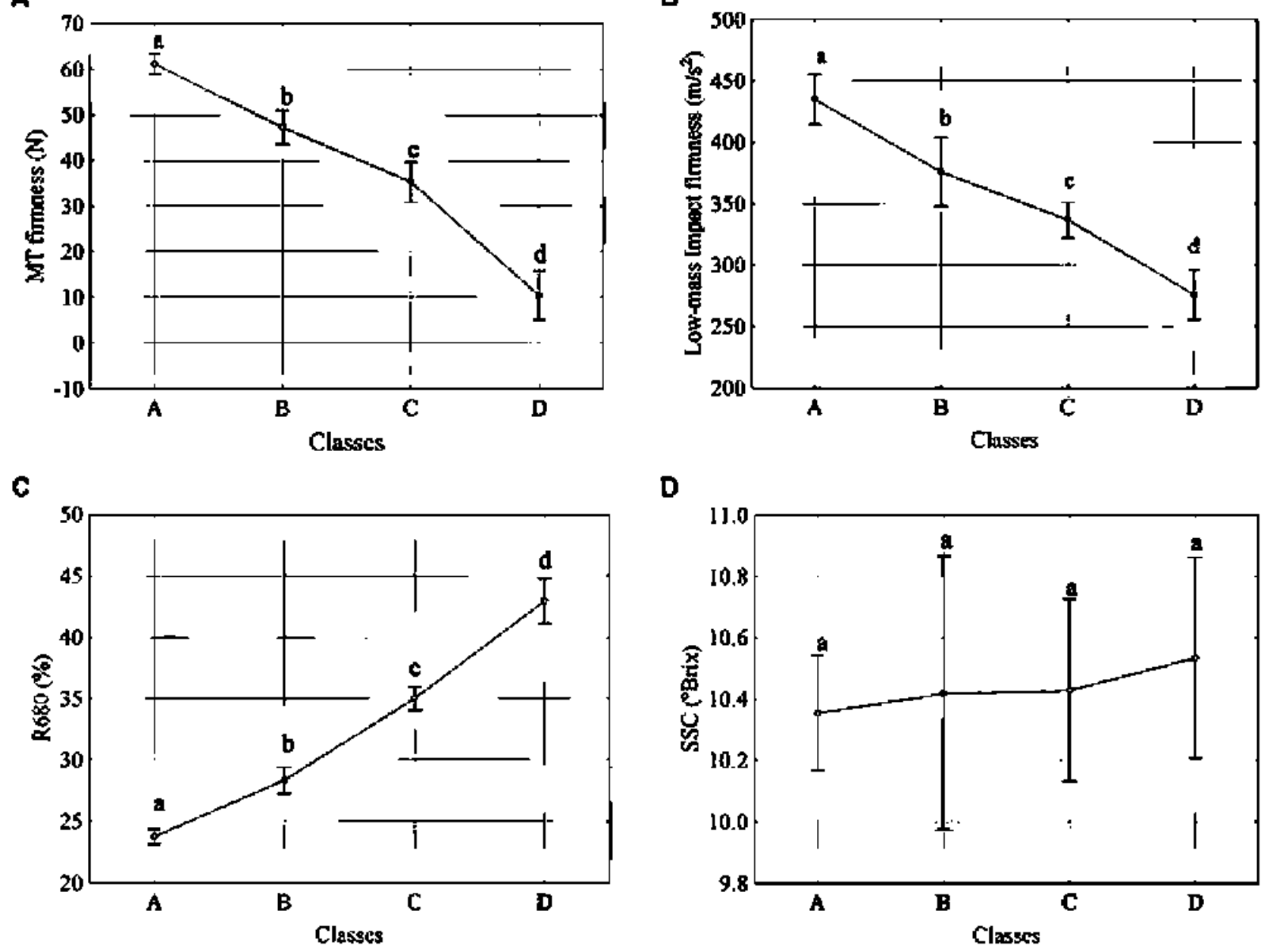

D

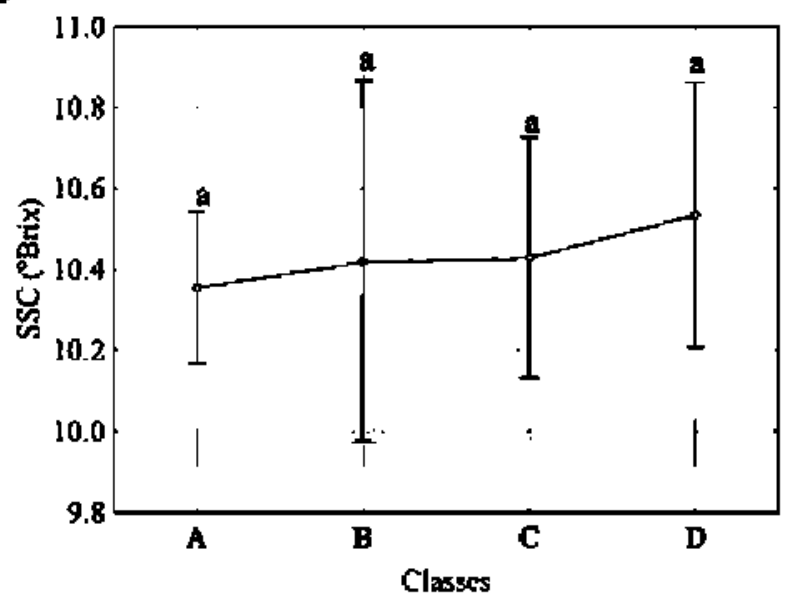

Figure 7-Plot of averages and confidence intervals (95\%) of 147 samples from season 2 classified in classes A to D according to Ward's method: (A) Magness-Taylor (MT) firmness (N); (B) low-mass impact firmness $(\mathrm{m} / \mathrm{s} 2) ;(C)$ reflectance at $680 \mathrm{~nm}(\mathrm{R} 680$, in \%); (D) soluble solids content (SSC, in ${ }^{\circ}$ Brix). Lowercase letters represent significant differences between classes at $P<0.05$ according to Fisher's least significant difference (LSD) test. 
each season, were automatically rejected by the classification algorithm (see section 2.2.d), being considered out of the range of the model.

When considering MTF ranges for each class (data not shown), it was as well observed that $60 \%$ (season 1) and $65 \%$ (season 2) of the samples assigned to class $\mathrm{A}$ at harvest did not achieve ready to eat MTF values.

Other authors have observed the potential of local or spatially detailed spectral measurements for the prediction and monitoring of peach ripening. Ziosi and others (2008) used a spectral index $\left(I_{A D}\right)$ to grade 2 groups of Fayette peaches at harvest as onset of climacteric (class 1) and climacteric (class 2). Both groups evolved differently, according to MTF, along 0 to $60 \mathrm{~h}$ ripening at $25^{\circ} \mathrm{C}$. The greatest firmness differences were found from 12 to $36 \mathrm{~h}$, when class 1 held its softening while class 2 average flesh firmness decreased. In our results, when LI firmness was monitored for $3 \mathrm{~d}$ at $20^{\circ} \mathrm{C}$, a similar effect was observed between the $2 \mathrm{nd}$ and $3 \mathrm{rd} \mathrm{d}$ of ripening, throughout which only class A maintained its average value (Figure 8). Hahn (2002) used spectral imaging to discriminate fruits (tomatoes) that will never ripe at the sorting line. In this case, color parameters could not be used to discriminate "immature" tomatoes, while more than $90 \%$ of them could be detected by hyperspectral $(490$ to $850 \mathrm{~nm})$, and $85 \%$ by multispectral image based on 8 wavebands.

\section{Conclusions}

This work proposes and validates a classification procedure for the assessment of peach ripeness into 4 categories (A to D) based on multispectral imaging. The proposed procedure would allow

Table 5-Image-based class after ripening process against class at harvest ( $n=60$ from season 2 ).

\begin{tabular}{lcccccc}
\hline & \multicolumn{7}{c}{ At harvest. Season 2.} \\
\cline { 2 - 8 } After ripening. OBSERVED & Cluster & A & B & C & D & 0 \\
\hline & A & 4 & 0 & 0 & 0 & 5 \\
& B & 1 & 0 & 1 & 0 & 0 \\
& C & 2 & 9 & 2 & 1 & 0 \\
& D & 1 & 1 & 19 & 2 & 0 \\
& 0 & 0 & 0 & 1 & 0 & 11 \\
\hline
\end{tabular}

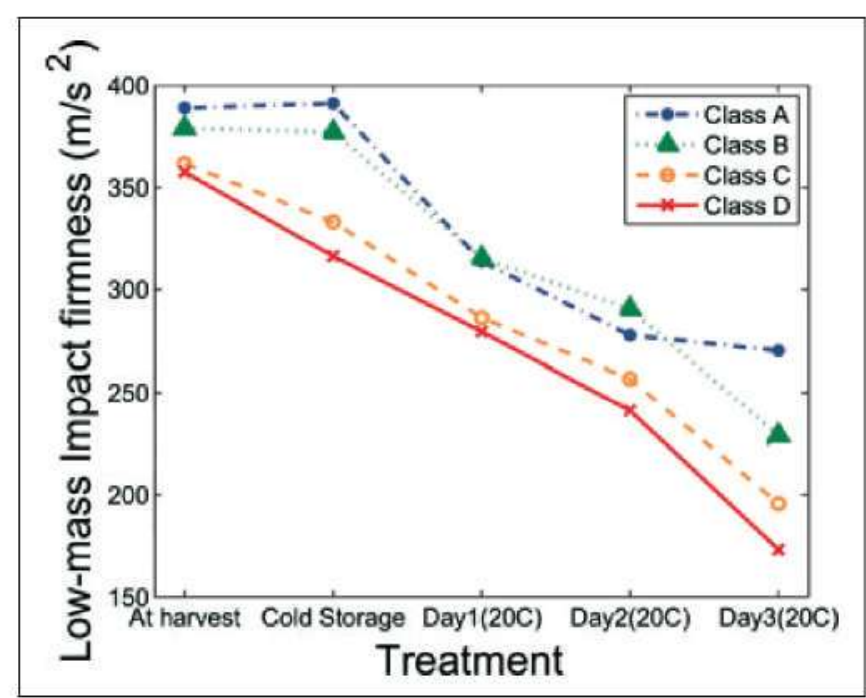

Figure 8-Average low-mass impact firmness values (m/s 2 ) monitored throughout 3 d ripening at $20^{\circ} \mathrm{C}(n=60)$. assigning unknown samples into image-based previously calibrated ripeness classes. The technology used is quick and ND, necessary characteristics to facilitate its future potential incorporation to online procedures. Nevertheless, the article only presents data for an imaging instrument for static analysis. Online applications still need of further research to optimize many influencing parameters. Image-based classes were related to MTF as the main current handling reference.

The robustness of the classification procedure was tested through external validation. An exclusion criterion, included in the classification algorithm, allowed recognizing and eliminating samples out of the range of the model. It was possible to classify images from fruits of 2 nd testing season with the model generated in the 1st season, obtaining similar average and range of MTF and 680 $\mathrm{nm}$ reflectance for the image-based classes. The model was able to identify $80 \%$ of peach images corresponding to either unmarketable soft firmness $(<18 \mathrm{~N})$ and to high-firmness fruits needing controlled ripening $(>53 \mathrm{~N})$. Those percentages were maintained even when using the model from a different season.

The image classification procedure allowed monitoring peach ripeness evolution. Class A could be associated with immature fruits, observing that $60 \%$ and $65 \%$ (season 1 and 2, respectively) of the samples assigned to class $\mathrm{A}$ at harvest did never achieve "ready to eat" firmness $(<18 \mathrm{~N})$ after $3 \mathrm{~d}$ of ripening. Class A maintained its average firmness after the 2 nd and subsequent days of ripening.

Results confirm the great potential of the proposed method to characterize the ripening state of peaches. It could be used as a potential rejection criterion for soft fruits (unmarketable for processing, distribution, and retailing) and for fruits needing controlled ripening treatments, showing high potential for its application in fresh peach packing lines.

\section{Acknowledgments}

This work was carried out in the frame of TAGRALIA-CM program, ISAFRUIT-EU 6th FP IP and MULTIHORT projects. The authors wish to thank Dr. F. Riquelme from CEBAS-CESIC (Spain) for his help with the selection of samples.

\section{References}

Basso B, Ritchic JT, Pierce FJ, Braga RP, Jones JW. 2001. Spatial validation of crop models for precision agriculture. Agric Syst 68(2):97-112.

Brosnan T, Sun D-W, 2004. Improving quality inspection of food products by computer vision-a review. J Food Eng 61(1):3-16.

Byrne DH, Nikolic AN, Burns EE, 1991. Variability in sugars, acids, firmness, and color characteristics of 12 peach genotypes. J Am Soc Hortic Sci 116:1004-6.

Camps C, Christen D. 2009. Non-destructive assessment of apricot fruit quality by portable visible-near infrared spectroscopy. LWT Food Sci Technol 42(6):1125-31.

Carlomagno G, Capozzo L, Attolico G, Distante A. 2004. Non-destructive grading of peaches by near-infrared spectrometry. Infrared Phys Technol 46(1-2):23-29.

Cascales AI, Costell E, Romojaro F. 2005. Effects of the degree of maturity on the chemical composition, physical character istics and sensory attributes of peach (Prusus persica) cv. Caterin. Food Sci Technol Intl 11(5):345-52.

Cemagref, Centre national du machinisne agricole, du génie rural, des eaux et des forêts. 1982. Le qualité gustative des fruits. Methodes pratiques d'analyse. Cemagref Inform Techniques $46(2): 4$.

Couvillon CO, Krewer G. 1991. The peach, the nectarine, and the plum. Quality and preservation of fruits. Boca Raton, Fla.: CRC Press. p 97-123.

Crisosta $\mathrm{CH}$. 1994. Stonefruit maturity indices: a descriptive review. Post harvest news inform 5:64-8.

Crisosto $\mathrm{CH} .1996$. Optimum procedures for ripening stone fruit. Managenent of ripening fruit. Postharvest Hortic 9:28-30.

Crisosto CH. 2002. Tips to increase peach consumption. Central Valley Postharvest Newsletter 11(1):1-5.

Crisosto CH. 2006. Peach quality and postharvest technology. Acta Hortic 713:479-87.

Crisosto CH, Slaughter DC, Garner D, Boyd J. 2001. Stone fruits critical bruising thresholds. J Am Pomol Soc 55(2):76-81.

Chalmers D, Ende B. 1975. A reappraisal of the growth and development of peach fruit. Funct Plant Biol 2(4):623-34.

Chen P, Ruiz-Altisent M. 1996. A low mass impact sensor for high-speed firmness sensing of fruits. International conference on agricultural engineering and industry exhibition. Madrid: Paper nr 96F-003. 
Chen Y-R. Chao K. Kim MS. 2002. Machine vision technology for agricultural applications. Comput Electronics Agric 36(2-3):173-91.

Delwiche M. Baumgnituer RA. 1993. Ground colour measurements of peach. I Am Soc Hortic Sci 108: $1020-16$.

Delwiche M. Tang S. Rumsey JW. 1997. Color and optical properties of elingstone peaches related to maturity. Am Soc A.grtic Eng $31(6): 1873-9$.

Dieuna-Iglesias B. Valero C, Garcin-Ramos Fi. Ruiz-Altisent M. 2006. Monitoring of tirmness evolution of peaches during stomge by combining acoustic and impact methods. J Food Eng $77(4): 926-35$.

Du C.-I. Sun D-W. 2006. Learning techniques used in computer vision for food quality evaluation: a review. J Food Eng 72(1):39-55.

Ferrer A. Remón S. Negueruela AI. Oria R. 20,05. Changes during the ripening of the very late season Spanish peath cultivar Calanda: feasibility of using CIELAB coordinates as maturity indices. Sci Hortic 105(4):435-46.

Gutierrez A. Burgos JA, Moltó E. 2(x)7. Pre-commercial sorting line for peaches firmnes assessonent. J Food Eng 81(4):72 I-7.

Hahn F 2002. AE-Automation and emerging technologies: multi-spectral prediction of unripe tomatoes. Biosyst Eng 81(2):147-55.

Herrero A. Lleó L. Valero C. Ruiz-Altisent M, Riquelme F. 2(w)7, Evaluación de técnicas no destructivas para I a caracterizacion de firmeza en melocotón. Actas de IV Congreso Nacional de Agroingenieria. Altacete 374-5.

Hui-Fuang, N. 2006. Automatic thresholding for defect detection. Pattern Recognit Lett $1644-9$.

Lleó L. Barreiro P, Ruiz-Altisent M, Herrero A. 2009. Mudtispectral images of peach related to furmness and maturity at harvest. J Food Eng 93(2):229-35.

Lleó L. Cordero S. Barreiro P. Ruiz-Altisent M. Riquelme F. 20(6). Peach multispectral images related to furmness and ripeness. Interiational Conferente on Agritultural Engrieeting ant Intustry Exhitition. Boml Book of Abstracts.

Lles L, Diezma B, Ruiz-Altisent M, Hetrero A, Valero C, Barreiro P, Riqueline F, OrtizCanavate J. 2007. Multispectral vision and mechanical semsors for pench quality inspection. 3nt International Commission of Agricultural Engineering (C.IGR) Section VI International Symposium on Food and Agricultural Products. processing and Innovations. Naples. Italy: Book of Atstricts.

Match E, Stocth L, Bosi T, Lod1 D. 20nis. Ottofrutta 1taliana. Fetrara: CSO, Centro Serviz Ortofrutticoli.

Mercasa. 2008. Frutas y hortalizas. Informe sobre produccion, industria, distribución y consunu de alimentación en españ. $2 \mathrm{M}$. $112-82$.

Merzlyak MN, Solovchenko AE, Gitelson AA. 2003. Reflectance spectral teatures and nondestructive estimation of thlorophyll, carotenoid and anthocyanin content in apple fortit. Postharvest Biol Technol 27(2):197-211.

Ministerio de Medio Rural y Maruio de España: MMARM. 2007. Hethos y cifras sobre agriculturn. 9th ed. Madrid: la Pesca y la Alimentación en España.

Otsu N. 1979. A threshold selection method from gray-level lustogtams. IEEE Trans Syst Man C.ybern $9: 62-6$.
Otto M. 20)7. Statistics and computer application in analytical chemistry, 2nd ed. Chichester. Perris KHS, Dull GG, Leffler RG, Kays SJ. 1998. Near-unfrared spectrometric method for nondestructive determination of solutle solids content of peaches. I Am Soc Hortic Sc $123(5): 898-905$.

Pérez-Marín D, Sánchez M-T, Paz P. Soriano M-A. Guerrero I-E, Garrido-Varo A. 20019. Non-destruttive determination of uluality parameters in nectarules during on-tree ripening and postharvest stomge. Postharvest Biol Technol 52(2);190-A.

Rekik A. Zribi, M. Hamida, AB, Benjelloun M. 2(w)7, Review of satellite image segmentation for an optinal fustion system based on the edige and region approathes. Int I Comput Sic1 Network Secur $7(10): 242-50$.

Ruiz-Altisent M, Lleó L. Riųuelme F. 2006. Instrumental quality assessment of peaches' fusion of optical and mechanical parameters. J Food Eng 74(4):490-9.

Ryall AL, Pentzer WT. 1982. Handling, transportation and storage of frutb and regetables. Fruits \& tee nuts. Westport. Conm.; AVI Publishing Co.

Salunkhe DK, Deshpande. PB. Do TY. 1968. Eftects of ripeness and storage on fhysical and brochemical thanges in peach and apricot fruits. J Hortic Sc1 43:235-42.

Scottond IM. Miller PCH. 2005. Applications of spectral reflectance techniques in northern European tereal production: a review. Biosyst Eng 9)(3):235-50.

Slaughter DC, Thompson IF, Tan ES, 20/33. Nondestructiwe determination of total and soluble solits in fresh pruhe wing near infrared spectroscopy. Postharvest Biol Teclurol 28(3):43744.

Tijskens LMM, Zerbin PE, Schouten RE, Vanol1 M, Jacob S, Grassi M1, Cubeddu R. Spinell L. Torricelli A. 2007. Assessing harvest maturity in nectaruies. Postharvest Biol Teslunol $45(2): 204-13$

Valero $\mathrm{C}$, Crisosto $\mathrm{CH}$. Slaughter D. 2(017. Relationship between nondestructive firmness measurements and commercially important ripening fuit stages for peaches, nectar ines and pluns. Postharvest Biol Teslurol 44(3):248-53.

Whrd JH, Ir. 1963. Hienarchical grouping to optimize an objective function. I Am Statist Assn $58: 236-44$.

Wu BH, Quilot B, Geinard M, Kervella J. Li SH. 20/5, Changes in sugar and organic acid concentrations dering truit maturation in peaches. $P$. dhvidiana and hytrids as analyzed by principal component analysis. Sci Hortic 103(4):429-39.

Xue L. Yang L. 2009. Deriving leat chlorophyll content of green-leafy vegetatles fiom hyperspectral reflectance. ISPRS I Photogtam Remote Sensing. In press.

Zack GW. Rogers, WE, Latt SA. 1977. Automatic measurement of sister chromatid exchange freciuency. I Histochem Cytorhem 25 (7):741-53.

Zheng C. Sun D-W. Zheng L. 2006 . Recent afplications of image texture for ewaluation of food qualities-a review. Trends Food Sci Technol 17(3):113-28.

Z1osi V. Noferun M, Fiori G, Tadiello A, Tranotti L, Casadoro G, Costa G. 2008. A new ind $x$ based on vis spectroscopy to characterize the propression of ripening in peach fruit. Postharvest Biol Tetiunol 49(3):319-29.

Zude-Sasse M. Trupfel I, Herold B. 2002. An afproach to non-destructive afple truit chlorophyll deterinination. Postharvest Biol Tetlunol 25(2):123-33. 